\title{
The use of the BIM method for sustainable care of historic buildings: Methodological framework
}

\author{
Stanislav Vitasek ${ }^{*}$ \\ Czech Technical University in Prague, Faculty of Civil Engineering, Czech Republic
}

\begin{abstract}
The article presents the use of the Building Information Modelling (BIM) method applied to historic buildings (HBIM). This is a very current topic with a direct link to the development of digital innovations. The HBIM approach presented in the article is primarily targeted at the owners/managers of historic buildings where its greatest expected benefit for this type of buildings is, in particular, in Facility Management. The key output of the article is the group of proposed parameters, which represents the requirements for the data on the part of both the facility manager, and the public authorities collecting selected information about historic buildings. As an example, the proposed parameters were applied to the All Saints' Church, where the "BIM technologies" were used for the elaboration of the project documentation.
\end{abstract}

Keywords: BIM, Digital Innovation Development, Facility Management, HBIM, Historic Building.

\section{Introduction}

The article presents the use of the Building Information Modelling (BIM) method in the context of sustainable care of immovable heritage buildings. The linking of the BIM approach to historic buildings is referred to as Historic Building Information Modelling (HBIM) in professional sources. The BIM approach, in general, is currently a topic of intensive research across the whole building industry thus representing the digital development of the segment. $[1,2]$

The BIM/HBIM (hereinafter referred to as BIM) method presented in the article is primarily targeted at the owners/managers of historic buildings, where its greatest expected benefit for this type of buildings is, in particular, in Facility Management (FM). A wellexecuted digital model of a building significantly simplifies the building management process, not only due to the standardized information format across the owner/manager portfolio. [3, 4] The objective of the article is to present, at the basic methodological level, how this standardized format (of comprehensive and structured data) can be captured with the use of the key parameters that should be part of the digitization process of the project documentation of individual historic buildings for the purposes of a subsequent database processing. The model application of the method to a historic building is performed on a medieval church, which has recently undergone renovation and selected "BIM (digital) technologies" have been applied to it primarily for the purpose of compiling the existing-

\footnotetext{
${ }^{*}$ Corresponding author: stanislav.vitasek@,fsv.cvut.cz
} 
conditions, design and as-built project documentation. In the article itself, however, the author focuses on how to fill the digital building model (BIM model; an example of a church in a digital environment - Fig. 1) with data, primarily with non-graphical information, so that the data can be subsequently transferred from the BIM model to meet the data needs on the part of selected public authorities managing statistical and informative (basic) data on historic buildings, and the facility managers themselves.

Fig. 1. Historic building processed with the use of the BIM method

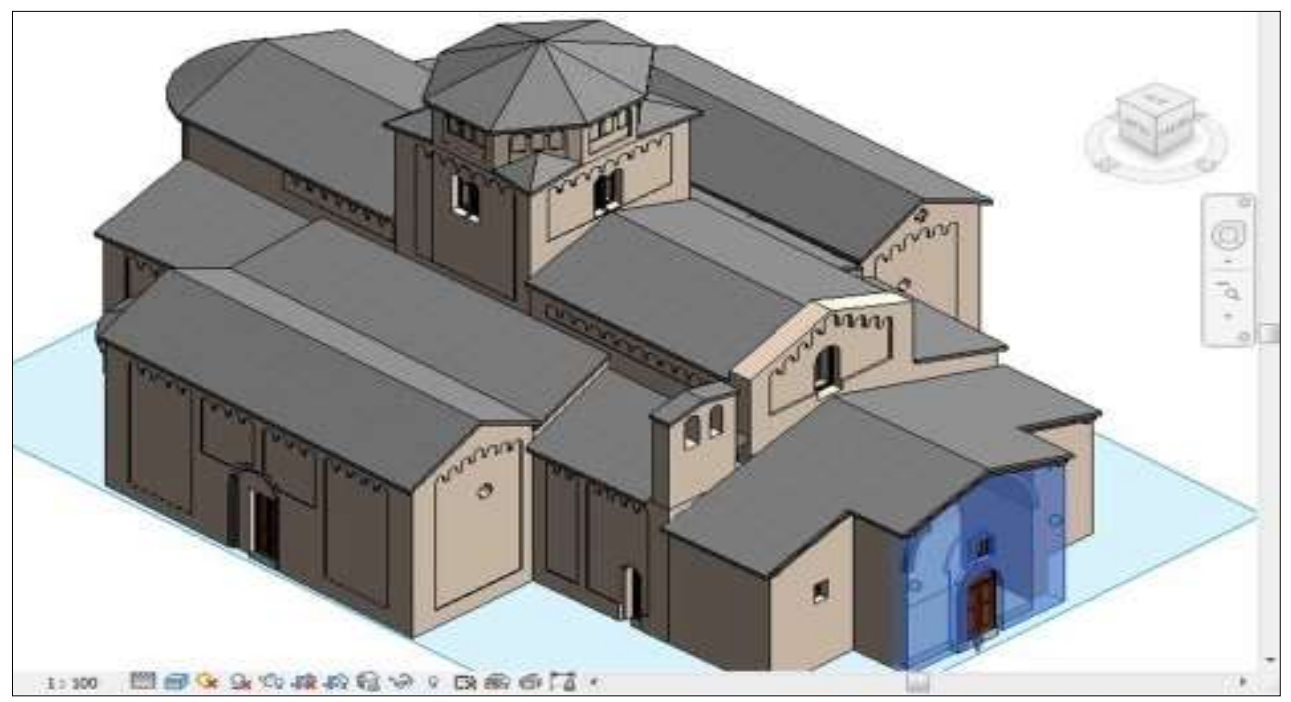

Source: ScienceDirect https://www.sciencedirect.com/science/article/pii/S1296207417300754\#fig0030.

\section{Literature review}

The Building Information Modelling is still perceived as a new concept in the construction sector, representing a significant technological progress in the information technology that has become apparent in recent years. It combines a digital environment with a real one with a great potential to change the traditional ways of work in the pre-project planning, construction and management phases of construction projects. The BIM method has several definitions coined by the leading experts in the construction industry and building associations. The most frequently quoted definition according to the author of the article is. The BIM technology produces one or more accurate, digitally generated virtual models of a building supporting the building's design throughout all phases of its life cycle, enabling more enhanced analyses and checks than manual (traditional) processes. When completed the computer-generated models contain the precise geometry and data needed for the construction, production and the procurement process according to which the building is delivered, including its subsequent implementation. [5] All interpretations connected with the BIM method definition generally have some common signs based on:

- sharing information between individual parties in the planning, construction and subsequent management of a built asset,

- 3D visualization and localization of structures or the entire building,

- faster decision-making associated with the project management and an overall higher economic efficiency of the project. 
The issues directly related to the topic of BIM and historic buildings are usually associated with specific buildings in professional publications. In this respect, an interesting article where a digital twin of a historic building was generated with the use of the "BIM technologies" and a scheme was subsequently designed for the integration of non-graphical data from the BIM model into the facility management system presents the St-Pierre-le-Jeune Church in Strasbourg (France). The scheme used there is inspiring for a basic overview of this topic, although some of the conclusions are the product of the time when it was published (2019). However, the mind map used to transfer data between the BIM model and the FM system is still relevant at the general level. [6] A similar article, but from the Italian environment, is associated with the historic structure of the Carlo III Bridge of the Carolino Aqueduct, where the BIM model again served as the source of information not only for the bridge management, but also for its restoration. The basic "BIM technologies" like the laser scanner, photogrammetry and topography were applied there. The article concludes by weighing the benefits of digital technologies against their drawbacks where the benefits of these advanced technologies unambiguously outweigh the drawbacks. [10] A different type of article, from the Spanish environment this time, compares the digital modelling of a historic building (the geometric aspect of the BIM model is primarily considered) of the Pavilion of Carlos V in Seville, which is executed in two ways. The first method represents the classic digitization of the existing project documentation, while the other applies the Point Cloud technology to survey the as-built layout of the building. The article concludes by comparing the different results in the building's geometry, where the authors identify the point cloud method as a more accurate way of generating a BIM model. [7] A similar study was also conducted by the colleagues from the Italian University of Naples Federico II and the Chinese Liming Vocat University, who dealt with the design of a parametric approach to the elaboration of methodologies for the digitization of heritage buildings with the use of the "BIM technologies". The result of their research can be expressed by the proverbial expression "less is more", as they recommend modelling simple geometric shapes of structures and including basic non-graphical information. [11, 13] A specialized study directly related to the design of the BIM model linked to the key execution document, the socalled BEP (BIM execution plan), was applied in the British environment. The authors focus on the essential points of the digital projection, particularly the graphic design, where they recommend the LOG 300 level for the passportization of historic buildings according to the Level of Development methodology. [8] An interesting article addresses the renovation projects of historic buildings, where the authors use selected algorithms and digital "BIM technologies" to design an optimum grid system for the restoration of a traditional Chinese building element. It is an intriguing way of using digital technologies, which can be easily transferred to any other building element. [9] A very practical study was conducted by the colleagues from the Polytechnic University of Valencia, who investigated several levels of the BIM method benefits for historic buildings: from the very design of the renovation project through visitor management and visitor protection to the digital promotion of the monument. The conclusions of their research recommend applying the BIM method on the widest possible scale. [12] However, according to the author of this article, some of the visions were too progressive and may only have a practical impact in a few years from now.

The operation of historic buildings in connection with long-term sustainable development is further addressed in studies $[14,15]$. The authors found that the operation and maintenance of historic buildings requires higher costs due to, for example, the need to respect historical technological procedures and historic building materials and take into account the opinion of the office of monument care. 


\section{Digital model of a building}

The digital model of a building serves as the key pillar of the BIM method. The BIM model can represent a database of information from the pre-project planning, construction, operational and maintenance phase, i.e. covering the entire life cycle of a construction work. In the context of historic buildings, the BIM models will most likely include primarily the information associated with different facility management and statistical requirements. The BIM model itself, therefore, represents a significant part of the project documentation in the format of graphical and non-graphical information (for more detail see the subchapters below). The key agent involved in the standardization of this information is referred to as the Data Standard for Buildings (DSB). Based on DSB, a BIM model is generated.

Based on the type of building structure and trades (structural system, sanitary engineering, electrical installations, etc.), the digital model of a building is usually divided into individual partial digital models of the building. The data from all partial BIM models are integrated in the so-called BIM coordination model [4]. Within the thematic scope of the article, the author did not focus on the overall concept of building information management, which is a more complex framework for the BIM method capturing the respective processes, communication, data sharing, etc. Our primary topic is the information related to the digital model of a building, which is of the greatest benefit for the management of historic buildings.

\section{$4 \mathrm{HBIM}$ - basic requirements for information}

In the perspective of the owner/manager of a historic building, as has been mentioned repeatedly in the text, the BIM method is beneficial primarily for the facility management of the building. The key phase before generating the BIM model itself is the identification of the data (depending on the subsequent use of the data), which the owner/manager needs to "collect" for FM and, based on these requirements, the compilation of a "data cookbook" for the designer (DSB). In other words, DSB incorporates both the graphical requirements for the virtual form of the structures/technologies in the digital environment (so-called elements), and the requirements for the non-graphical information (e.g. for individual items of the passport system). This means that the resulting BIM model frequently also contains, in addition to the graphical representation of the building, the more substantial non-graphical information assigned to each element representing the structure/technology.

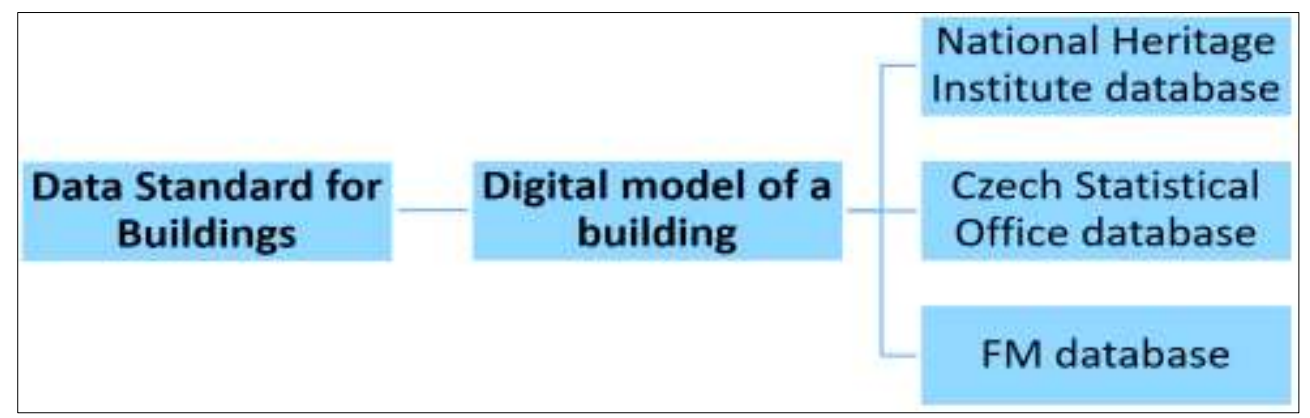

Fig. 2. Links between the DBS, digital model of a building and individual databases Source: Own processing. 
The non-graphical information can be divided into two basic types. Firstly, there are complex (common) parameters containing information about the building as a whole, and, secondly, data assigning specific (partial) properties (parameters) to individual structures/technologies in the building. Within the scope of the article, the author addresses the first group of common parameters in more detail, i.e. the situation where the same set of information is assigned to all the elements in the BIM model (Chapter 4.3). Explicitly, in the case of the renovation of the All Saints' Church, the data needed by selected public authorities managing the statistical and informative (basic) data on historic buildings and by the facility manager are presented (an illustrative scheme of data linkage is part of the scheme above Fig. 2). On the contrary, the group of sub-parameters unique to each type of structure/technology is approached more generally in the article (Chapter 4.4).

\subsection{Laser scanning and photogrammetry}

The key "BIM technology" in relation to the generation of BIM models of not only historic buildings is laser scanning. It is a process in which we obtain accurate information about the scanned object by means of determining its spatial coordinates. Individual points carry information based mostly on the principle of the spatial polar method. Hence, each point is identified by the oblique length, the horizontal angle, the zenith angle, and it can also carry the colour shade value. The result is a point cloud that is transformed into a BIM model (sample output in the Fig. 3).

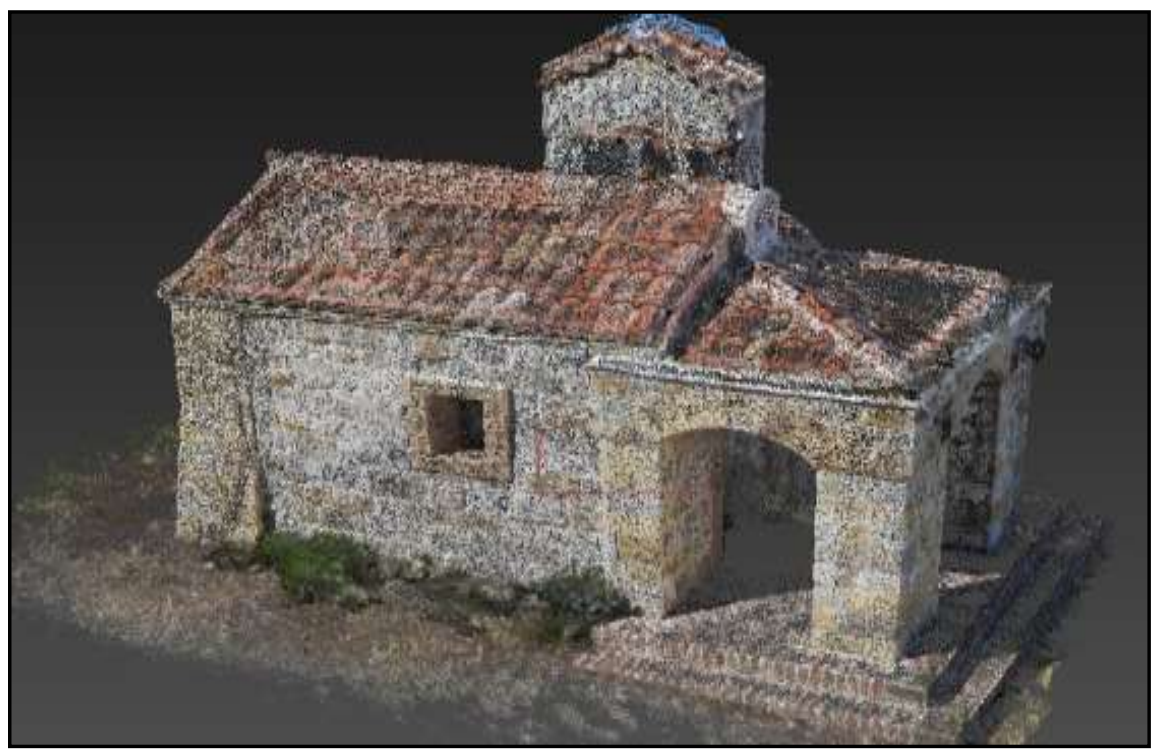

Fig. 3. Example of a laser scanning result - point cloud

Source: Autodesk http://docs.autodesk.com/3DSMAX/16/ENU/3ds-Max-Help/images/GUID-B3A18050-A7414CA6-85F4-9683C8CBB4B-low.png.

Another technology beneficial for mapping historic buildings is photogrammetry, whose surveys are most often performed with the help of drones and airplanes. It is a measurement method used for contactless collection of data on the Earth's surface, i.e. the process of remote sensing and measurement, mostly during a flight. After the information is collected 
in the field, a point cloud and, subsequently, a BIM model of the object are created from the photographs and other data.

\subsection{Graphical information}

Graphical information specifies the type of drawing, graphics, location in space, scale, shape, etc. In the case of requirements for graphical data, due to the absence of national standards, most creators of "BIM data" usually refer to the international method of marking the graphical levels according to the Level of Geometry (LOG) method. LOG determines the geometric level of detail of the BIM model or its individual elements (structures/technologies processed in the virtual environment) for various phases of the project documentation, and thus defines which parts of structures/technologies should be drawn in the model and which should not. The scale is usually from LOG 100 to LOG 400 (for an example of a model structure see the figure below - Fig. 4), where the detail of the documentation for the building permit is recommended at the LOG 300 level, while for the documentation for the construction process and building passports, the recommended version of detail is LOG 350 .

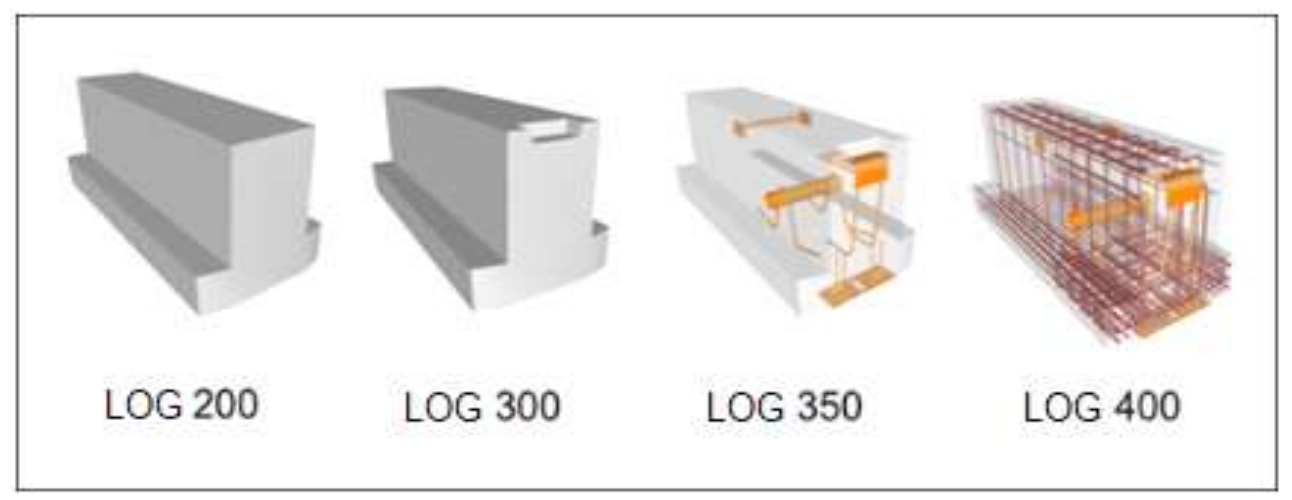

Fig. 4 Example of graphical information levels of detail in LOG

Source: Areo blog https://blog.areo.io/content/images/2016/12/LED-BIM-example.png.

Each increase in the geometric level of detail also proportionally increases the complexity and the time needed for the BIM model generation. This is subsequently reflected in the cost of its creation, too. Therefore, it is advisable to consider the required detail in relation to the subsequent use carefully.

\subsection{Non-graphical information - common parameters}

Non-graphical information generally enables the description of individual characteristics of a building which are usually not graphically expressed. These are, above all, names, dimensions, areas, additional information about the building, etc. In international methodologies, the level of detail of non-graphical information is referred to as the Level of Information (LOI). In principle, it works in the same way as the LOG method in the case of the demands for graphics. 
The common parameters represent the properties (parameters) at the identification level of the whole historic building for which the BIM model is being created. Hence, it is a group of parameters that will be part of all elements integrated into the digital model of the building. The identification of the key information for facility management requires some experience in working with this process, therefore, the author of the article drew on the required data on historic buildings collected by the National Heritage Institute (NHI), the Czech Statistical Office (CSO) and the Roman Catholic Church ( $\mathrm{RCCH}$ ). NHI and CSO manage their data in a database, which is fully compatible with the BIM method concept, which itself is based on a database environment. This implies that there may be a smooth (automated) data transfer between the BIM model and the NHI and CSO databases. In principle, the proposed method of work is applicable to any public and private companies working in database environments.

Table 1. Common parameters for the All Saints' Church

\begin{tabular}{|c|c|c|c|}
\hline Property & Format & $\begin{array}{l}\text { Requirement for } \\
\text { information }\end{array}$ & Historic building \\
\hline Name of the building & Text & RCCH, NHI & All Saints' Church \\
\hline Origin & Text & RCCH, NHI & $13^{\text {th }}$ century \\
\hline State & Text & $\mathrm{RCCH}$ & Czech Republic \\
\hline Region & Text & $\mathrm{RCCH}, \mathrm{NHI}$ & Usti nad Labem Region \\
\hline District & Text & $\mathrm{RCCH}, \mathrm{NHI}$ & Litomerice \\
\hline Municipality & Text & RCCH, NHI & Litomerice \\
\hline Cadastral Territory & Text & RCCH, NHI & Litomerice \\
\hline Address & Text & $\mathrm{RCCH}, \mathrm{NHI}$ & Dlouha; Jezuitska \\
\hline $\begin{array}{l}\text { Classification of Types of } \\
\text { Constructions }(\mathrm{CZ}-\mathrm{CC})\end{array}$ & Number & $\mathrm{CSO}$ & 127211 \\
\hline $\begin{array}{l}\text { Classification of Buildings } \\
(\mathrm{KSO})\end{array}$ & Number & $\mathrm{CSO}$ & 80147 \\
\hline $\begin{array}{l}\text { Catalogue Number I } \\
\text { (Building's ID) }\end{array}$ & Number & $\mathrm{RCCH}$ & 895484 \\
\hline $\begin{array}{l}\text { Catalogue Number II } \\
\text { (Building's ID) }\end{array}$ & Text & NHI & $21077 / 5-1748$ \\
\hline $\begin{array}{l}\text { Catalogue Number III } \\
\text { (Building's ID) }\end{array}$ & Text & $\mathrm{CSO}$ & $57481-544-5$ \\
\hline $\begin{array}{c}\text { Historical (architectural) } \\
\text { style }\end{array}$ & Text & NHI & Gothic; Baroque \\
\hline Type of heritage care & Text & $\mathrm{NHI}$ & Cultural Monument \\
\hline Subject to heritage care since & NUM & $\mathrm{NHI}$ & 1958 \\
\hline Type of building & Text & $\mathrm{NHI}$ & Church \\
\hline $\begin{array}{c}\text { Number of overground } \\
\text { stories }\end{array}$ & Number & $\mathrm{RCCH}$ & 1 \\
\hline $\begin{array}{c}\text { Number of underground } \\
\text { stories }\end{array}$ & Number & $\mathrm{RCCH}$ & 0 \\
\hline Enclosed area & Number & $\mathrm{RCCH}$ & 563 \\
\hline Built-up area & Number & $\mathrm{RCCH}$ & 125 \\
\hline Floor area & Number & $\mathrm{RCCH}$ & 110 \\
\hline
\end{tabular}

Source: Own processing.

Table 1 displays the information required by both the public authorities (NHI and CSO) and the facility manager $(\mathrm{RCCH})$. For example, NHI has the need to classify historic buildings based on their purpose, namely in accordance with the national classification system labelled the Classification of Buildings (KSO) used in the conservation practice, and, on the contrary, the needs of CSO are incorporated in the Classification of Types of Constructions (CZ-CC). The information needed by RCCH was identified by the author by 
selecting it from the FM System's database, which is used by RCCH. It includes the properties related primarily to the location and the dimensional characteristics of buildings.

\subsection{Non-graphical information - type (partial) parameters}

The second group of properties is associated with the specific requirements of individual structures/technologies for specific information. Typically, this is the type of data related to material parameters, dimensional characteristics, service life, etc. Compared to the first group of Common Parameters, this group is significantly larger in volume. This is primarily due to the wide range of the used building materials and the different execution technologies. The interest on the part of individual public authorities (NHI and CSO) in this information also significantly differs. Or, sometimes, it is almost zero. In contrast, the facility manager (RSC)

\begin{tabular}{|c|c|c|c|}
\hline Property & Format & Description & Historical object \\
\hline Structure's Marking & Text & - & brick wall \\
\hline Structure's Origin & Number & Presumed year of structure's making & - \\
\hline Last Modification & Number & $\begin{array}{c}\text { Presumed year of } \\
\text { renovation/modernization }\end{array}$ & - \\
\hline Element Code & Number & $\begin{array}{c}\text { Classification of building structures } \\
\text { and technologies }\end{array}$ & 35864 \\
\hline Structure's Condition & Text & $\begin{array}{c}\text { Current condition of the structure } \\
\text { (choices - good, neglected, } \\
\text { dilapidated) }\end{array}$ & good \\
\hline Structural Function & Text & $\begin{array}{c}\text { Indicates the element's structural } \\
\text { function (choices - load-bearing, non- } \\
\text { load-bearing) }\end{array}$ & non-load-bearing \\
\hline Element's Location & Text & $\begin{array}{c}\text { Indicates the element's location } \\
\text { (choices - inside, outside) }\end{array}$ & inside \\
\hline Surfacing - Inside & Text & The type of surface treatment used & lime plaster \\
\hline Surfacing - Outside & Text & The type of surface treatment used & cement plaster \\
\hline Thickness & Number & $\begin{array}{c}\text { Numerical value of the element's } \\
\text { thickness in mm }\end{array}$ & 300 \\
\hline Height & Number & $\begin{array}{c}\text { Numerical value of the element's } \\
\text { height in mm }\end{array}$ & 2600 \\
\hline
\end{tabular}

is interested in these data. $\mathrm{RCCH}$ can subsequently use the data actively for facility management, the planning of renovations and other activities.

Table 2. Type parameters - a brick wall

Source: Own processing.

The specification of the relevant parameters for individual structures/technologies suitable for the passport of historic buildings (issues related to DSB) is beyond the scope of this article, and, therefore, only one example of potential parameters for a brick wall is included (Table 2). In historic buildings, it is usually difficult to fill in some of the required parameters, which are usually commonly available only for newly built or not very old buildings. These are typically the parameters like the Origin, the Last Modification of the Structure, etc.

\section{Conclusion}

The article presents, at the basic methodological level, how the BIM model can be data linked with various database tools using a specific historical building (All Saints' Church), which has recently been renovated, as an example. The "BIM technologies" at the point cloud level 
were applied to compile the project documentation during its renovation. The author of the article has designed a group of non-graphical information (Common Parameters) for the generated BIM model. In the design of specific parameters for the All Saints' Church, the author was inspired by the key authorities that already work with the data on a regular basis and require them from the owners of buildings (i.e. CSO and NHI). These parameters, in turn, further complement the requirements set by the historic building's facility manager (RCCH), who also collects selected data about the owned buildings in a database. The key output of the article is Table No. 1, which displays the proposed Common Parameters.

In general, HBIM represents another specific digitization branch of the building industry (thematically with a direct link to the development of digital innovations), which needs to be conceptually elaborated in adequate detail to achieve the required efficient processing of information needed for sustainable immovable heritage conservation. The work method proposed in the article is principally applicable to any public and private companies that work in database environments. The database-processed data and their automated transfer from one database to another represents a modern way of working advisable primarily for the organizations managing quite a few buildings.

\section{References}

1. P. Matejka, Utilization of digitized Building Data and Information Models (BIM) in value estimation of building in rural areas. 18th International Scientific Conference on Engineering for Rural Development (ERD), pp. 1693-1698 (2019)

2. G. Rocha, L. Mateus, J. Fernandez, V. Ferreira, A Scan-to-BIM Methodology Applied to Heritage Buildings. Heritage, 3(1), 47-65 (2020)

3. R. Bouska, R. S. Heralova, Opportunities for use of advanced visualization techniques for project coordination. 6th Creative Construction Conference (CCC), pp. 1051-1056 (2017)

4. M. Stransky, P. Dlask, Process of matching work items between bim model and cost estimating software. 17th International Scientific Conference on Engineering for Rural Development (ERD), pp. 856-864 (2018)

5. CH. M. Eastman, BIM handbook: a guide to building information modeling for owners, managers, designers, engineers and contractors. 2nd ed. Hoboken: Wiley (2011)

6. X. Yang, Y. Lu, A. Murtiyoso, M. Koehl, P. Grussenmeyer, HBIM Modeling from the Surface Mesh and Its Extended Capability of Knowledge Representation. ISPRS International Journal of Geo-Information, 8(7), 301 (2019)

7. J. E. Nieto-Julia, D. Anton, J. J. Moyano, Implementation and Management of Structural Deformations into Historic Building Information Models. International Journal of Architectural Heritage, 14(9), 1384-1397 (2020)

8. D. Heesom, P. Boden, A. Hatfield, S. Rooble, K. Andrews, H. Berwari, Developing a collaborative HBIM to integrate tangible and intangible cultural heritage. International Journal of Building Pathology and Adaptation, 39(1), 72-95 (2021)

9. J. Yang, X. Wang, C. Wu, C. Bai, Regularized Reconstruction of Grid System for Traditional Chinese Timber Structure Building in HBIM. International Archives of the Photogrammetry, Remote Sensing and Spatial Information Sciences, 42-2(W15), 12291233 (2019)

10. A. Conti, L. Fiorini, R. Massaro, C. Santoni, G. Tucci, HBIM for the preservation of a historic infrastructure: the Carlo III bridge of the Carolino Aqueduct. Applied Geomatics (2020) 
11. M. Capone, E. Lanzara, Scan - to - BIM vs 3D Ideal Model HBIM: Parametric Tools to Study Domes Geometry. International Archives of the Photogrammetry Remote Sensing and Spatial Information Sciences, 42-2(W9), 219-226 (2019)

12. E. Salvador-Garcia, Integrating HBIM models in the management of the public use of heritage buildings. Canadian Journal of Civil Engineering, 47(2), 228-235 (2020)

13. L. Zhang, Research on Protection and Restoration of Heritage Buildings Based on Heritage Building Information Model (HBIM) Technology and Its Application. Advances in Social Science Education and Humanities Research, 417, 239-245 (2020)

14. E. Hromada, R. S. Heralova, P. Dlask, T. Krulicky, Methodology for Calculating the Reproduction Value of Buildings. Innovative Economic Symposium 2020 - Stable Development in Unstable World, 91, 1034 (2021)

15. D. Macek, R. S. Heralova, E. Hromada, I. Strelcova, L. Brozova, S. Vitasek, J. Pojar, R. Bouska, Cost Optimization for Renovation and Maintenance of Cultural Heritage Objects. IOP Conference Series: Earth and Environmental Science, 290, 12155 (2019) 